\title{
НЕКОТОРЫЕ ПРАКТИЧЕСКИЕ АСПЕКТЫ АНАЛИЗА МЕЖФЛЮИДНЫХ КОНТАКТОВ ПРИ ГЕОЛОГИЧЕСКОМ МОДЕЛИРОВАНИИ ЗАЛЕЖЕЙ НЕФТИ И ГАЗА.
}

Кавун М.M., Степанов А.В., Истомин С.Б. $(O A O \ll Ц(T Э »)$

Реферат Обобщен опыт пространственной геометризации поверхностей межфлюидных контактов при геологическом моделировании залежей углеводородов. Проиллюстрированы основные типы гидродинамических экранов, их признаки, различные способы приведения межсфлюидных контактов $к$ горизонтальной поверхности в цифровых моделях залежей, либо объяснения их негоризонтальности. Даны рекомендации по применению этих способов в наиболее распространённых ситуациях.

C начала прошлого века геологи-нефтяники при создании пространственных моделей залежей нефти и газа столкнулись с проблемой геометризацин межфлюидных контактов, которые в пределах гидродинамически единьх резервуаров теоретически должны быть горизонтальными. Однако на практике такие контакты, к сожалению, встречаются весьма редко, что обусловлено рядом причин как геологического характера, так и связанных с неоднозначностью исходной геолого-геофизической информацик. Вопрос этот имеет ключевое значение, так как напрямую влияет на конфигурацию залежей в плане, расчётные объемы запасов УВ и все остальные ключевые параметры залежей, по которым рассчитываются технологические схемы их разработки. Важно отметить, что в Российской Федерации все построенные модели залежей в конечном счёте проходят экспертизу государственных контролируюших органов, где существуют весьма жёсткие требования к обоснованию геометрии контактов. Ниже приведено конспективное изложение стандартной методики анализа ВНК/ГВК, которая необходима всем геологам, занимающимся цифровым моделирование залежей УВ. Поскольку в настоящее время фактически обязательным этапом ГРР при регламентных работах являются сейсмические исследования, мы подразумеваем наличие таких данных.

Первое, что надо сделать при выявлении значимой (более 2-3 м) разности уровней контактов в пределах a priory единой залежи - проверить всю исходную информацию, касаюпуюся геометрии проблемньх скважин (т.е. тех, где значения отличаются от фоновых), пространственного положения пересечённых ими границ резервуара, и характера насыщения коллектора. Это следующие основные неоднозначности:

1. Ошибки в координатах устьев скважин; 2 . Ошибки в альтитудах; 3. Ошибки в инклинометрин; 4. Неоднозначность определения характера насыщения коллектора по данным ГИС и опробования; 5. Анализ истории разработки; 6. Неоднозначности в корреляция продуктивных пластов по кривым ГИС в скважинах.

Если изучение всех перечисленных неоднозначностей не принесло результата, а анализируемая залежь изначально рассматривается в качестве единого объекта (резервуара), можно попытаться объ-

яснить наблюдаемую негоризонтальность поверхности контакта. Перечислим следуюшие известные нам объяснения:

1. Наличие блоков с различной пористостью коллектора; 2. Интенсивный гидродинамический напор; 3. Различные свойства нефтей (плотность, вязкость)

Очевидно, пто кзложенные факторы могут оказывать существенное влияние на наклон контактов лишь при достаточно большой плошади залежей. Однако в большинстве случаев исследователи имеют дело с мелкими и средними месторождениями, которые приходится расчленять на блоки с разным уровнем контактов.

4. Недосформированные (неравновесные) залежи.

Обоснование разделения резервуаров на блоки с различными ВНК.

Итак, если не удалось аппроксимировать контакт субгоризонтальной поверхностью, либо удовлетворительно обосновать причины его негоризонтальности, при моделировании обычно приходится расчленять залежь на гидродинамически изолированные блоки. Наиболее часто для этого используется структурный, тектонический и литологический факторы.

Необходимо отметить, что все перечисленные пути объяснения/корректировки негоризонтальных контактов имеют вполне определённые границы применения. На практике встречаются ситуацин, когда использование всех этих способов не позволяет корректно решить проблему, т.е. получить в рамках общепринятых геологических представлений приемлемое и достаточно обоснованное объяснение имеющейся фактической информации. Для достоверной интергретации на площадях, где встречено незакономерное изменение уровня межфлюидных контактов, недропользователям приходится производить дополнительные и достаточно затратные исследования: повторные испытания в скважинах, замеры инклинометрии современными гироскопами, гидропрослушивание для выявления экранов в межскважинном пространстве, сейсморазведку ЗД для прогнозирования зон глинизации и объективного трассирования тектонических нарушений, и т.д.

Совершенно очевидно, однако, тто в природе существуют разновидности гидродинамических экранов, о которых мы пока не имеем представления, а можем лишь констатировать их наличие во многих резервуарах. Таким образом, необходимы дальнейшие теоретические исследования в этом награвлении, которые позволят сделать качественный прорыв в решении этого важнейшего практического вопроса. 